\title{
Accessing safe drinking water in sub-Saharan Africa: Issues and challenges in South-West Nigeria
}

\author{
C.P. Emenike ${ }^{\mathrm{a}, *}$, I.T. Tenebe ${ }^{\mathrm{a}}$, D.O. Omole ${ }^{\mathrm{a}}$, B.U. Ngene ${ }^{\mathrm{a}}$, B.I. Oniemayin ${ }^{\mathrm{a}}$, O. Maxwell ${ }^{\mathrm{b}}$, \\ B.I. Onoka ${ }^{\mathrm{c}}$ \\ a Department of Civil Engineering, College of Engineering, Covenant University, Ota, Ogun State, Nigeria \\ ${ }^{\mathrm{b}}$ Department of Physics, College of Science and Technology, Covenant University, Ota, Ogun State, Nigeria \\ c Department of Accountancy, University of Nigeria, Nsukka, Enugu State, Nigeria
}

\section{A R T I C L E I N F O}

\section{Article history:}

Received 13 July 2016

Accepted 11 January 2017

Available online 4 February 2017

\section{Keywords:}

Safe water

Water quality

SDGs

Household

WaSH

\begin{abstract}
A B S T R A C T
Termination of the Millennium Development Goals gave birth to the Sustainable Development Goals (SDGs) with which Target 6 is to provide unhindered access to safe and economical drinking water and sanitation for all. The survey in this research adopted stratified sampling technique that captured 400 households, in which 700 well-structured questionnaire consisting of open and closed-ended questions were distributed. The questions were in line with Water and Sanitation Hygiene (WaSH) recommendations on drinking water and sanitation for household surveys. It examined the access to safe water regarding accessibility, availability, affordability and acceptability in Ado-Odo Ota, Ogun State, Nigeria. Personal interviews were conducted to capture the emotional discretion of respondents towards the subject matter. Cross-tabulation and Multinomial logit model were used to analyze the relationship of the variables on water access. The results obtained showed that the water access within the study area is mostly limited to the private sources because of the level of quality and accessibility. The study reveals that the fate placed on government water facilities has dwindled drastically. Furthermore, the study highlighted the need to revisit government policies, with the inclusion of subsidy, cost recovery and rainwater harvesting as effective tools in improving and encouraging equity in water access.
\end{abstract}

(c) 2017 Elsevier Ltd. All rights reserved.

\section{Introduction}

Water of good quality is required to maintain a clean environment, good health, and a healthy nation at large (Conant, 2005; Adams, Bartram, \& Chartier, 2008, Hunter, MacDonald, \& Carter, 2010, Palaniappan et al., 2010). However, limited access to safe drinking water, quality sanitation facilities, unhealthy hygiene practices and improper water management practices can promote the spread of water-borne diseases, which causes $6.3 \%$ of the deaths recorded around the world (WHO, 2008; Omole \& Ndambuki, 2014). Therefore, the access to adequate potable water is highly imperative to promote public social welfare and development (IPU, 1996; Joseph, 2012). It is estimated that approximately $9 \%$ of the people around the world lack access to potable water while 2.4 billion cannot adequately access quality sanitation facilities despite the coordinated global effort to actualize the MDG target (WHO/UNICEF, 2015). Likewise, in a report released by the

\footnotetext{
* Corresponding author.

E-mail address: praisegod.emenike@covenantuniversity.edu.ng (C.P. Emenike).
}

World Population Prospect (WPP) with the sole aim of achieving sustainable development with tools of demographic growth, it was estimated that Africa's population is expected to rise from 1.2 billion in 2015-1.7 billion in 2030, and further increase to 2.4billion will be recorded in 2050 (UNDESA, 2015).

From the time the MDGs was initiated (1990) to its expiration (2015), there have been increase in the use of improved water sources globally (from 76\% to 91\%), however, despite the coordinated efforts, much still need to be done as regards water access (WHO/UNICEF, 2015). Additionally, from the flag-off time till 2015, the current population that has gained access to water remains over $40 \%$ in sub-Sahara Africa. Sequel to the $20 \%$ increase in the use of improved water sources experienced in sub-Saharan Africa from 1990 to 2015, there still lie a huge gap in access within this region with major concentration of the population living in rural areas. In a recent report outlined by the UNICEF/WHO Joint Monitoring Program (JMP), it is estimated that $79 \%$ of the rural population lack improved water sources whereas $93 \%$ rely on surface water for survival (Dempster, 2016; WHO/UNICEF, 2015).

On the other hand, after the cessation of the MDGs in September 2015 , the world focused on a new plan called the Sustainable Devel- 